\title{
The association between isoflavone and lower urinary tract symptoms in elderly men
}

\author{
Samuel Y. S. Wong ${ }^{1 *}$, Winny W. Y. Lau ${ }^{2}$, Ping C. Leung ${ }^{3}$, Jason C. S. Leung ${ }^{2}$ and Jean Woo ${ }^{1,4}$ \\ ${ }^{1}$ Department of Community and Family Medicine, School of Public Health, Prince of Wales Hospital, Shatin, N.T., Hong Kong \\ ${ }^{2}$ Jockey Club Centre for Osteoporosis Care and Control, The Chinese University of Hong Kong, Hong Kong \\ ${ }^{3}$ Department of Orthopaedics and Traumatology, The Chinese University of Hong Kong, Hong Kong \\ ${ }^{4}$ Department of Medicine and Therapeutics, The Chinese University of Hong Kong, Hong Kong
}

(Received 8 December 2006 - Revised 2 May 2007 - Accepted 18 May 2007)

The objective of the present study is to explore the association between lower urinary tract symptoms (LUTS) and dietary isoflavone in elderly men. In a large prospective cohort of 2000 Chinese men, the association between dietary isoflavone and LUTS were studied using standardized structured questionnaires. Dietary intake was assessed by a modified version of the Block FFQ. LUTS were assessed by the Chinese version of the International Prostatic Symptoms Score. Demographic, lifestyle and other medical information were also collected and were adjusted for in the analysis. After excluding 299 men with history of bladder surgery, bladder or prostate cancer or who were current users of medication for urinary problems, the association between LUTS and dietary isoflavone was explored. A total of $96.2 \%$ of subjects reported some consumption of genistein, glycitein or daidzein. In ordinal multinominal logistic regression, subjects with dietary total isoflavone of more than $5 \cdot 1 \mathrm{mg}$ were significantly less likely to suffer from more severe LUTS (dietary intake from 5.1 to $9.5 \mathrm{mg}$ : OR 0.59 ; $95 \%$ CI $0.44,0.80$; from 9.6 to $14.3 \mathrm{mg}$ : OR $0.81 ; 95 \%$ CI $0.61,1.09$; from 14.4 to $21.7 \mathrm{mg}$ : OR $0.68 ; 95 \%$ CI $0.51,0.92 ; 21.8 \mathrm{mg}$ and above: OR $0.73 ; 95 \%$ CI 0.54 , 0.98 ) after adjustment for covariates. In this cross-sectional study, we showed a strong inverse association between dietary intake of isoflavone and the risk of LUTS.

Cross-sectional studies: Benign prostatic hyperplasia: Diet: Isoflavone: Urology diseases

Benign prostatic hyperplasia (BPH) is a prevalent problem in elderly men. Although the prevalence of microscopic BPH is the same in men of all races ${ }^{1}$, the prevalence of clinical BPH was shown to be significantly higher in elderly Caucasian men than in Asian men ${ }^{2}$. Isoflavone, a form of phyto-oestrogen, has been suggested as a candidate that can account for this difference in prevalence. Besides the marked differences in the dietary intake of isoflavone between Westerners and Asians ${ }^{3}$, isoflavone also possesses biochemical properties that can affect prostate physiology.

Biochemically, isoflavones are heterocyclic phenols structurally similar to the oestrogenic steroids and possess weak oestrogenic and antioestrogenic properties ${ }^{4}$. As a result, isoflavones can potentially affect hormone-dependent growth in men that includes prostate cancer and BPH.

Although these earlier studies suggest that the lower prevalence of clinical BPH observed in Asian men may be related to the higher consumption of isoflavone in their diets, to the authors' knowledge, no large epidemiological studies have directly explored the association between dietary isoflavone intake and $\mathrm{BPH}$ or symptoms related to prostatic hyperplasia in a large community cohort. The current study is therefore conducted to evaluate the association between the intake of isoflavone and lower urinary tract symptoms (LUTS) in a large sample of elderly Chinese men.

\section{Materials and methods}

Study subjects

In total 2000 Chinese men who were 65 years and older were recruited for a study of osteoporosis in Chinese men. All subjects were able to walk independently as this is one of the inclusion criteria to the study. Stratified sampling was adopted in order to have around $33 \%$ of subjects in each of the following age groups: $65-69,70-74, \geq 75$ years. Recruitment notices were placed in housing estates and community centres for the elderly. Subjects were invited to the research centre for interviews and physical examination. Interviews were performed by trained researchers using a standardized, structured questionnaire which addressed mutiple aspects, including demographics, medical history, lifestyle and eating habits. Informed consent was obtained from all subjects. For this analysis, men with a history of bladder or prostate cancer or 
surgery for bladder cancer were excluded. Men who regularly take $\alpha$-blockers, $5 \alpha$-reductase inhibitors, anti-androgen or medications for treating neurogenic bladder were also excluded as these may affect the presentation of LUTS and may confound the results. The study was approved by the ethics committee of the Faculty of Medicine of the Chinese University of Hong Kong.

\section{Questionnaire}

Subjects were interviewed using a standardized, structured questionnaire which covered the following aspects.

General characteristics. Information on age, address, place of origin, education levels and occupation was obtained.

Overall health and medication. Information on subjects' medical history was obtained based on self-reports of medical conditions. Subjects were asked to bring in all medications for identification.

Dietary intake. Dietary intake was assessed by a modified version of the Block FFQ, based on data obtained in the Hong Kong Adult Dietary Survey in $1995^{5} ; 285$ dietary items were included in the questionnaire. Mean nutrient quantitation per day was calculated using food tables derived from McCance $\&$ Widdowson's: The Composition of Foods ${ }^{6}$ and the Chinese Medical Sciences Institute ${ }^{7}$. For the measurement of soya content, the questionnaire included ten soya items commonly consumed by the Hong Kong Chinese population that included soyabean, canned soyabean, soft tofu, firm tofu, deep-fried tofu, tofu-pop, bean curd skin, bean curd sheet, soya milk and vitasoy (a common brand of soyamilk consumed by the Hong Kong population). Isoflavone content in soya products was estimated based on published data ${ }^{8,9}$.

Lower urinary tract symptoms. The presence and severity of LUTS was assessed by the locally validated Chinese version of the International Prostatic Symptoms Score ${ }^{10,11}$ for LUTS. The International Prostatic Symptoms Score assesses nocturia, frequency, urgency, intermittency, weak stream, incomplete emptying and straining.

Using standard cut-points for symptom severity, men were defined as having severe LUTS if they scored 20 or more on the International Prostatic Symptoms Score. They were defined as having moderate LUTS if they scored from 8 to 19.Mild LUTS were defined as having a score of 7 or less.

Cigarette smoking and alcohol consumption. Information on the duration and amount of past and current use of cigarettes, cigars and pipes were obtained. Smoking status was defined as former smoker (at least 100 cigarettes smoked in a lifetime), current smoker and those who never smoke. For current smokers, the number of cigarettes smoked per day over the previous 12 months was categorized as $<20$ or $\geq 20$.

For alcohol consumption, subjects were asked to report their daily frequency of intake of alcohol and other beverages in portion sizes. They were also asked to report on how many days of the week they consumed alcohol. Drinking status was defined as never, former or current drinker. Current drinkers were defined as those who drank at least twelve drinks of beer, wine (including Chinese wine), or liquor over the previous 12 months. One standard drink was defined as one unit of alcohol which is equal to $10 \mathrm{~g}$ alcohol. For beer, one standard drink equals one can of beer $(330 \mathrm{ml})$ which is equivalent to one glass of wine $(100 \mathrm{ml})$ which is equal to one shot of spirit or liquor $(30 \mathrm{ml})$.

Physical activity. Physical activity was measured by the validated Physical Activity Scale for the Elderly Questionnaire $^{12}$. It measured the level of physical activity in individuals aged 65 years and older. The instrument is a self-report/interview-based measure designed to capture and assess occupational, household and leisure activities typically performed by older adults. This was adapted to Hong Kong Chinese by adding activity items which were popular in the local culture.

\section{Statistical analysis}

The frequency and amount of isoflavone intake in different age groups are presented in descriptive statistics. A $\chi^{2}$ test was used to test for association between isoflavone intake and age and education levels. As total isoflavone intake could be affected by total energy intake of the individual, total isoflavone intake was adjusted for energy intake for all analyses by residual method. The median energy-adjusted total isoflavone $(\mathrm{mg})$ intake among subjects with different LUTS status (none, mild, moderate and severe) were compared by using Wilcoxon rank sum tests as the distribution of isoflavone intake was skewed. Univariate analyses and stepwise backward multivariate analyses were used to investigate the associations between isoflavone intake and LUTS. Energyadjusted isoflavone intake was divided into quintiles and LUTS were categorized into none, mild, moderate and severe. OR and its $95 \% \mathrm{CI}$ for having a more severe degree of LUTS as being related to energy-adjusted total isoflavone intake $(\mathrm{mg})$ were analysed using ordinal multinomial logistic regression. All variables that were shown to be significantly associated with severity of LUTS were entered into the final regression model as covariates. Other covariates in the regression included socio-demographic factors (age and education levels), lifestyle factors (alcohol consumption, physical activity) and medical factor (history of CVD and depression) that have been shown to be related to LUTS in the literature and in our previous study on risk factors for LUTS. All statistical analyses were performed using the statistical package SAS, version 8.02 (SAS Institute, Cary, NC, USA). An $\alpha$ level of 0.05 was used as the level of significance.

\section{Results}

Of the 2000 men recruited, 299 men were excluded as they had either history of bladder surgery, history of bladder or prostate cancer, were current users of $\alpha$-blockers, anti-androgen or medications for urinary problems. The demographic characteristics of the remaining 1701 men were shown in Table 1. These characteristics were compared to those obtained from the Thematic Household Survey, a population-based survey on a random sample of the Hong Kong population conducted by the Department of Census and Statistics $^{13}$ of the Hong Kong SAR every 5 years in Hong Kong. It shows that subjects in Mr Os were more educated and were more likely to be married when compared to that of the general population in the same gender and age range. The majority of men were married or living with a partner $(88.3 \%)$. More than half had only a primary or lower 
Table 1. Characteristics of subjects ( $n$ 1701)

\begin{tabular}{|c|c|c|}
\hline Variable & Mean & SD \\
\hline Total isoflavone $(\mathrm{mg})^{*}$ & $5 \cdot 73$ & $23 \cdot 13$ \\
\hline Median value & 11.47 & \\
\hline Age (years) & $72 \cdot 2$ & $5 \cdot 0$ \\
\hline $\mathrm{BMI}$ & $23 \cdot 4$ & $3 \cdot 1$ \\
\hline \multicolumn{3}{|l|}{ Marital status (\%) } \\
\hline Single, never married & $2 \cdot 0$ & \\
\hline Married or living in a married-like relationship & $88 \cdot 3$ & \\
\hline Divorced/separated/widowed & $9 \cdot 7$ & \\
\hline Current alcohol use (\%) & $24 \cdot 3$ & \\
\hline \multicolumn{3}{|l|}{ Smoker (\%) } \\
\hline Non-smoker & $36 \cdot 3$ & \\
\hline Past smoker & $50 \cdot 7$ & \\
\hline Current smoker & $12 \cdot 9$ & \\
\hline PASE score & $98 \cdot 1$ & 51.5 \\
\hline \multicolumn{3}{|l|}{ Education (\%) } \\
\hline Primary or below & $60 \cdot 9$ & \\
\hline Secondary/matriculation & $25 \cdot 5$ & \\
\hline University or above & 13.5 & \\
\hline
\end{tabular}

PASE, Physical Activity Scale for the Elderly Questionnaire.

${ }^{*}$ Energy-adjusted by residual method.

education $(60.9 \%)$. Overall, $12.9 \%$ were current smokers with half having a past history of smoking $(50.7 \%)$. Most subjects were non-drinkers $(75.7 \%)$. Only $1.8 \%$ consumed at least 14 drinks per week.

The energy-adjusted intake of dietary genistein, glycitein, daidzein and total isoflavone are summarized in Table 2; $96.2 \%$ of subjects reported consumption of genistein, glycitein or daidzein. As the distribution of dietary intake of isoflavone was skewed, both median and mean energy-adjusted dietary intakes of isoflavone were presented as summary measures. Table 3 showed the comparision between median intake of energy-adjusted total isoflavone $(\mathrm{mg})$ and severity of LUTS.

Table 4 presents demographic, lifestyle and medical characteristics across different levels of energy-adjusted intake of total isoflavone per day $(\mathrm{mg})$ and the corresponding $P$ values of ANOVA for continuous variables and $\chi^{2}$ tests for categorical variables.

In ordinal multinominal logistic regression, subjects with dietary intake of total isoflavone of more than $5.1 \mathrm{mg}$ were significantly less likely to suffer from LUTS after adjustment for covariates (Table 5 and 6) that included age, secondary

Table 2. Mean and median values $(\mathrm{mg} / \mathrm{d})$ of energy-adjusted dietary intakes of daidzein, genistein and glycitein ( $n$ 1701)

\begin{tabular}{lcccc}
\hline Variables & Median & IQ range & Mean & SD \\
\hline Daidzein & & & & \\
$\quad$ Entire sample & 4.07 & 4.64 & 5.57 & 8.43 \\
$\quad$ Non-zero intake & 4.22 & 4.64 & 5.78 & 8.51 \\
Genistein & & & & \\
$\quad$ Entire sample & 7.00 & 8.22 & 9.61 & 13.66 \\
$\quad$ Non-zero intake & 7.24 & 7.97 & 9.96 & 13.78 \\
Glycitein & & & & \\
$\quad$ Entire sample & 0.33 & 0.51 & 0.56 & 1.51 \\
$\quad$ Non-zero intake & 0.42 & 0.56 & 0.68 & 1.67 \\
$\quad \begin{array}{l}\text { Total isoflavone } \\
\quad \text { Entire sample }\end{array}$ & 11.47 & 13.23 & 15.73 & 23.13 \\
$\quad$ Non-zero intake & 11.90 & 13.14 & 16.30 & 23.35 \\
\hline
\end{tabular}

Table 3. Energy-adjusted total isoflavone (mg) among subjects with different lower urinary tract symptom (LUTS) status

\begin{tabular}{|c|c|c|c|c|}
\hline \multirow[b]{2}{*}{ Total isoflavone (mg) } & \multicolumn{4}{|c|}{ LUTS status } \\
\hline & $\begin{array}{c}\text { None (0) } \\
(n 94)\end{array}$ & $\begin{array}{c}\text { Mild } \\
(1-7) \\
(n 968)\end{array}$ & $\begin{array}{c}\text { Moderate } \\
(8-19) \\
(n 544)\end{array}$ & $\begin{array}{c}\text { Severe } \\
(20+) \\
(n 95)\end{array}$ \\
\hline Mean & $16 \cdot 7$ & 14.6 & 13.8 & 13.1 \\
\hline SD & 13.5 & $13 \cdot 6$ & $12 \cdot 6$ & $12 \cdot 4$ \\
\hline Median & $13 \cdot 3$ & $11.4^{*}$ & $11.2 \dagger$ & $11 \cdot 1 \neq$ \\
\hline
\end{tabular}

Median value was significantly different from that of the no LUTS group (Wilcoxon rank sum test): ${ }^{\star} P=0.0424$

Median value was significantly different from that of the no LUTS group (Wilcoxon rank sum test): $\dagger P=0.0199$.

Median value was significantly different from that of the no LUTS group (Wilcoxon rank sum test): $\ddagger P=0.0235$.

education or above, Physical Activity Scale for the Elderly Questionnaire score, current alcohol use, depression and CHD status: for those with dietary intake from 5.1 to $9.5 \mathrm{mg}$ (OR $0.59 ; 95 \%$ CI $0.44,0.80$ ); from 9.6 to $14.3 \mathrm{mg}$ (OR $0.81 ; 95 \%$ CI $0.61,1.09$ ); from 14.4 to $21.7 \mathrm{mg}$ (OR 0.68 ; $95 \%$ CI $0.51,0.92$ ); from $21.8 \mathrm{mg}$ and above (OR 0.73; $95 \%$ CI 0.54, 0.98). To explore a possible threshold for energy-adjusted total intake of isoflavone, an ordinal multinominal logistic regression analysis was also conducted with energy-adjusted isoflavone as a dichotomous variable $(<5.1 \mathrm{mg} v .5 .1 \mathrm{mg}$ or above).

\section{Discussion}

In this cross-sectional study, we demonstrated that dietary intake of isoflavone was associated with decreased risk of LUTS. Most epidemiological studies on the relationship between phyto-oestrogen and prostate in men have been focused on prostate cancer ${ }^{14}$. Few studies have directly explored the association between phyto-oestrogen and BPH or protatic symptoms per se. A study conducted by Hong et al. ${ }^{15}$ showed that isoflavone and lignan levels in the prostate tissues of Korean men were significantly lower in those with small benign prostates compared to those with enlarged benign prostates. Brossner et al. ${ }^{16}$, in a sample of sixty-three men with BPH, showed that genistein tissue levels were significantly greater in men with small-volume BPH when compared with those with large-volume BPH. However, in both studies, confounding factors that included age, BMI and physical activity were not accounted for.

For animal studies, previous findings were conflicting for rats or mice that were fed on isoflavone diet of regular content ${ }^{17}$. However, in a recent study conducted in aromatase knockout mice that were fed an isoflavone-rich diet (similar to $80-100 \mathrm{mg} / \mathrm{d}$ ), Jarred et al. ${ }^{18}$ showed that those that were fed an isoflavone-rich diet had a reduction of prostate weight when compared to aromatase knockout mice that were fed an isoflavone-free diet.

We found that those with energy-adjusted total isoflavone intake of more than or equal to $5.1 \mathrm{mg}$ have decreased risk of having LUTS although no dose-response relationship was seen in the analysis using logistic regression. It should be noted that a dietary intake of $5.1 \mathrm{mg} / \mathrm{d}$ is not high and is much lower than the average dietary intake of Japanese 
Table 4. Characteristics among subjects with different lower urinary tract symptom (LUTS) status

\begin{tabular}{|c|c|c|c|c|c|c|c|c|c|}
\hline \multirow[b]{3}{*}{ Variable } & \multicolumn{9}{|c|}{ LUTS status } \\
\hline & \multicolumn{2}{|c|}{ None $(0)(n 94)$} & \multicolumn{2}{|c|}{ Mild (1-7) (n 968) } & \multicolumn{2}{|c|}{$\begin{array}{l}\text { Moderate (8-19) } \\
\quad(n 544)\end{array}$} & \multicolumn{2}{|c|}{$\begin{array}{l}\text { Severe }(20+) \\
\quad(n 95)\end{array}$} & \multirow[b]{2}{*}{$P$ value* } \\
\hline & Mean & SD & Mean & SD & Mean & SD & Mean & SD & \\
\hline \multicolumn{10}{|l|}{ Total isoflavone intake (\%)† } \\
\hline$<5.1 \mathrm{mg}$ & $9 \cdot 6$ & & $18 \cdot 9$ & & $22 \cdot 9$ & & $25 \cdot 3$ & & 0.018 \\
\hline $5.1-9.5 \mathrm{mg}$ & 24.5 & & $20 \cdot 8$ & & $18 \cdot 8$ & & $14 \cdot 7$ & & \\
\hline $9.6-14.3 \mathrm{mg}$ & $19 \cdot 2$ & & $19 \cdot 6$ & & $19 \cdot 6$ & & $27 \cdot 4$ & & \\
\hline $14.4-21.7 \mathrm{mg}$ & $20 \cdot 2$ & & $21 \cdot 3$ & & $18 \cdot 1$ & & $16 \cdot 8$ & & \\
\hline $21.8 \mathrm{mg}$ or above & $26 \cdot 6$ & & $19 \cdot 4$ & & $20 \cdot 7$ & & $15 \cdot 8$ & & \\
\hline \multicolumn{10}{|l|}{ Demographics } \\
\hline Age (years) & 71.5 & 4.7 & 71.9 & 4.8 & $72 \cdot 8$ & $5 \cdot 1$ & 73.2 & $5 \cdot 8$ & 0.0048 \\
\hline Weight (kg) & $61 \cdot 9$ & $9 \cdot 0$ & $62 \cdot 4$ & $9 \cdot 1$ & $62 \cdot 2$ & $9 \cdot 7$ & 59.5 & $10 \cdot 0$ & 0.0663 \\
\hline BMI & 23.3 & $3 \cdot 0$ & 23.4 & $3 \cdot 0$ & 23.5 & 3.3 & $22 \cdot 5$ & 3.3 & 0.1227 \\
\hline Secondary education or above (\%) & $53 \cdot 2$ & & 42.5 & & $33 \cdot 1$ & & $24 \cdot 2$ & & $<0.0001$ \\
\hline \multicolumn{10}{|l|}{ Lifestyle } \\
\hline Energy intake $(\mathrm{kJ} / \mathrm{d})$ & 8974.7 & $2437 \cdot 2$ & 8878.9 & $2502 \cdot 0$ & $8677 \cdot 6$ & $2456 \cdot 8$ & 8614.0 & $2292 \cdot 0$ & 0.2383 \\
\hline Energy intake $(\mathrm{kcal} / \mathrm{d})$ & $2145 \cdot 0$ & 582.5 & $2122 \cdot 1$ & 598.0 & 2074.0 & 587.2 & $2058 \cdot 8$ & $547 \cdot 8$ & 0.2383 \\
\hline PASE score & $118 \cdot 1$ & 62.5 & $100 \cdot 4$ & $52 \cdot 2$ & 91.9 & $47 \cdot 1$ & 93.5 & $50 \cdot 0$ & 0.0003 \\
\hline Current smoker (\%) & $20 \cdot 2$ & & $12 \cdot 6$ & & $11 \cdot 8$ & & $15 \cdot 8$ & & 0.988 \\
\hline Current alcohol use (\%) & $25 \cdot 5$ & & $26 \cdot 5$ & & $21 \cdot 7$ & & $16 \cdot 8$ & & 0.007 \\
\hline \multicolumn{10}{|l|}{ Medical history (\%) } \\
\hline Depression & $6 \cdot 4$ & & $5 \cdot 2$ & & $12 \cdot 5$ & & $16 \cdot 8$ & & $<0.0001$ \\
\hline Stroke & $4 \cdot 3$ & & 5.0 & & $5 \cdot 7$ & & $6 \cdot 3$ & & 0.404 \\
\hline $\mathrm{CHD}$ & $4 \cdot 3$ & & 13.5 & & 19.5 & & $16 \cdot 8$ & & 0.005 \\
\hline Diabetes mellitus & 8.5 & & $14 \cdot 7$ & & $14 \cdot 3$ & & $11 \cdot 6$ & & 0.67 \\
\hline
\end{tabular}

PASE, Physical Activity Scale for the Elderly Questionnaire.

* $P$ value of ANOVA test for trend for continuous variables and $x^{2}$ test for trend for categorical variables where appropriate.

$\dagger$ Energy-adjusted by residual method.

subjects which was found to be more than $40 \mathrm{mg} / \mathrm{d}$. However, this is still considered to be much higher than Western diets which consist of dietary isoflavone of less than $1 \mathrm{mg} / \mathrm{d}$. The 'threshold' effect of these isoflavone levels and the risk of LUTS is unexpected, as studies conducted in rodents suggest that significant effects on non-malignant prostate growth can only occur in a diet with large amounts of isoflavone ${ }^{17}$.
There were several explanations for the findings. First, there were many causes of LUTS of which BPH is only one of them. Other causes include urinary tract infections, bladder neck hypertrophy, diabetes mellitus, cerebrovascular diseases, or bladder or prostate cancer. As a result, the relationship could have been confounded by these other factors, making the dose-response relationship not evident. To minimize the

Table 5. Ordinal multinomial logistic regression - model $1^{\star}$

\begin{tabular}{|c|c|c|c|c|c|c|c|c|c|c|}
\hline \multirow[b]{3}{*}{ Variable } & \multicolumn{9}{|c|}{ LUTS status } & \multirow[b]{3}{*}{$95 \% \mathrm{Cl}$} \\
\hline & \multicolumn{2}{|c|}{ None $(0)(n 94)$} & \multicolumn{2}{|c|}{$\begin{array}{l}\text { Mild (1-7) } \\
\quad(n 968)\end{array}$} & \multicolumn{2}{|c|}{$\begin{array}{c}\text { Moderate } \\
(8-19)(n 544)\end{array}$} & \multicolumn{2}{|c|}{$\begin{array}{l}\text { Severe }(20+) \\
\quad(n 95)\end{array}$} & \multirow[b]{2}{*}{ OR } & \\
\hline & Mean & SD & Mean & SD & Mean & SD & Mean & SD & & \\
\hline \multicolumn{11}{|l|}{ Total isoflavone intake (\%)† } \\
\hline$<5.1 \mathrm{mg}$ & $9 \cdot 6$ & & 18.9 & & 22.9 & & $25 \cdot 3$ & & 1 & \\
\hline $5.1-9.5 \mathrm{mg}$ & 24.5 & & $20 \cdot 8$ & & $18 \cdot 8$ & & $14 \cdot 7$ & & 0.59 & $0.44,0.80$ \\
\hline $9.6-14.3 \mathrm{mg}$ & $19 \cdot 2$ & & $19 \cdot 6$ & & $19 \cdot 6$ & & $27 \cdot 4$ & & 0.81 & $0.61,1.09$ \\
\hline $14.4-21.7 \mathrm{mg}$ & $20 \cdot 2$ & & 21.3 & & $18 \cdot 1$ & & $16 \cdot 8$ & & 0.68 & $0.50,0.91$ \\
\hline $21.8 \mathrm{mg}$ or above & $26 \cdot 6$ & & $19 \cdot 4$ & & 20.7 & & $15 \cdot 8$ & & 0.73 & $0.54,0.98$ \\
\hline Age, per 1 year & 71.5 & 4.7 & 71.9 & 4.8 & $72 \cdot 8$ & $5 \cdot 1$ & 73.2 & 5.8 & 1.03 & $1.01,1.05$ \\
\hline Secondary education or above (\%) & $53 \cdot 2$ & & 42.5 & & $33 \cdot 1$ & & $24 \cdot 2$ & & 0.63 & $0.52,0.77$ \\
\hline PASE score, per unit & 118.1 & 62.5 & $100 \cdot 4$ & $52 \cdot 2$ & 91.9 & $47 \cdot 1$ & 93.5 & $50 \cdot 0$ & 0.997 & $0.995,0.998$ \\
\hline Current alcohol use (\%) & 25.5 & & 26.5 & & $21 \cdot 7$ & & $16 \cdot 8$ & & 0.84 & $0.67,1.06$ \\
\hline Depression (\%) & $6 \cdot 4$ & & $5 \cdot 2$ & & 12.5 & & $16 \cdot 8$ & & $2 \cdot 18$ & $1.55,3.05$ \\
\hline $\mathrm{CHD}(\%)$ & 4.3 & & 13.5 & & 19.5 & & $16 \cdot 8$ & & 1.60 & $1.23,2.08$ \\
\hline
\end{tabular}

LUTS, lower urinary tract symptom; PASE, Physical Activity Scale for the Elderly Questionnaire.

${ }^{*}$ Results of ordinal multinomial logistic regression are presented as the OR of being in higher LUTS category.

†Energy-adjusted by residual method. 
Table 6. Ordinal multinomial logistic regression - model $2^{\star}$

\begin{tabular}{|c|c|c|c|c|c|c|c|c|c|c|}
\hline \multirow[b]{3}{*}{ Variable } & \multicolumn{8}{|c|}{ LUTS status } & \multirow[b]{3}{*}{ OR } & \multirow[b]{3}{*}{$95 \% \mathrm{Cl}$} \\
\hline & \multicolumn{2}{|c|}{ None $(0)(n 94)$} & \multicolumn{2}{|c|}{$\begin{array}{l}\text { Mild (1-7) } \\
\quad(n 968)\end{array}$} & \multicolumn{2}{|c|}{$\begin{array}{c}\text { Moderate } \\
(8-19)(n 544)\end{array}$} & \multicolumn{2}{|c|}{$\begin{array}{l}\text { Severe }(20+) \\
(n 95)\end{array}$} & & \\
\hline & Mean & SD & Mean & SD & Mean & SD & Mean sd & SD & & \\
\hline \multicolumn{11}{|l|}{ Total isoflavone intake (\%)† } \\
\hline$<5.1 \mathrm{mg}$ & $9 \cdot 6$ & & $18 \cdot 9$ & & 22.9 & & $25 \cdot 3$ & & 1 & \\
\hline Age, per 1 year & $71 \cdot 5$ & $4 \cdot 7$ & $71 \cdot 9$ & $4 \cdot 8$ & $72 \cdot 8$ & $5 \cdot 1$ & $73 \cdot 2$ & $5 \cdot 8$ & 1.03 & $1.01,1.05$ \\
\hline Secondary education or above (\%) & $53 \cdot 2$ & & $42 \cdot 5$ & & $33 \cdot 1$ & & $24 \cdot 2$ & & 0.63 & $0.52,0.77$ \\
\hline PASE score, per one unit & $118 \cdot 1$ & $62 \cdot 5$ & $100 \cdot 4$ & $52 \cdot 2$ & 91.9 & $47 \cdot 1$ & $93 \cdot 5$ & $50 \cdot 0$ & 0.997 & $0.995,0.999$ \\
\hline Current alcohol use (\%) & 25.5 & & 26.5 & & $21 \cdot 7$ & & $16 \cdot 8$ & & 0.85 & $0.68,1.07$ \\
\hline Depression (\%) & $6 \cdot 4$ & & $5 \cdot 2$ & & $12 \cdot 5$ & & $16 \cdot 8$ & & $2 \cdot 17$ & $1.55,3.04$ \\
\hline CHD (\%) & $4 \cdot 3$ & & $13 \cdot 5$ & & $19 \cdot 5$ & & $16 \cdot 8$ & & 1.61 & $1.24,2.09$ \\
\hline
\end{tabular}

LUTS, lower urinary tract symptom; PASE, Physical Activity Scale for the Elderly Questionnaire.

${ }^{\star}$ Results of ordinal multinomial logistic regression are presented as the OR of being in higher LUTS category.

$\dagger$ Energy-adjusted by residual method.

confounding from these factors, efforts were made in the current study to control for effects from these confounders. Those with history of prostate cancer, prostate surgery or those who took anti-androgen or $5 \alpha$-reductase inhibitors were excluded. Those with diabetes mellitus and cerebrovascular accidents were not shown to be significantly different in their severity of LUTS. However, as no laboratory tests or urodynamic tests were performed, no analysis could be performed to control for confounding from those with urinary tract infections or neurogenic bladder dysfunction. We also could not exclude the possibility that unmeasured confounding factors may be responsible for the relationship.

Second, there may be a threshold effect for the relationship between LUTS and dietary intake of isoflavone, although this has not been explored or supported in previous studies.

In a previous study, Jarred et al. ${ }^{18}$ suggested that significant effects on non-malignant prostate growth can only occur in those with large amounts of dietary isoflavone intake approximately equivalent to $80-100 \mathrm{mg} / \mathrm{d}$. However, their study was conducted in mice and thus might not be applicable to man.

Men in the West usually consume diets very low in isoflavone with data suggesting that their dietary intake of total isoflavone is probably $<5 \mathrm{mg}$ isoflavones/ $\mathrm{d}^{9,19}$. As a result, studies on the relationship between LUTS and isoflavone are more feasible in Asians, who on average consume a considerably higher amount of isoflavone. Strengths of the present study include the detailed and standardized assessment of dietary intake of isoflavone and LUTS and the large sample size of community-dwelling elderly men. Moreover, a large number of risk factors for LUTS in this population were measured and were adjusted in the final regression analysis, making the relationship observed more likely to be a true association.

The limitation includes its cross-sectional design, where the temporal relationship between dietary total isoflavone intake and LUTS was not known and unmeasured dietary factors or confounders could have been responsible for the results. Thus, no conclusion on causal relationships can be made. Furthermore, the men recruited in the present study were volunteers from the community and selection bias could not be avoided. Finally, we could not exclude the possibility that errors may occur in dietary recall as no laboratory assessments of tissue, urinary or serum isoflavone levels were assessed.

In summary, the present study found a strong, inverse association between dietary intake of total isoflavones and LUTS. It provides further evidence to suggest the beneficial effects of isoflavones for preventing or treating prostatic symptoms. The high prevalence of LUTS and prostatic problems in ageing men, the impact of LUTS on quality of life in these men, the healthcare costs associated with treating LUTS and the ageing of population all make investigating the relationship between isoflavone intake and LUTS worthwhile. Isoflavone supplementation may be an important public health tool for treating men with LUTS related to BPH. However, conclusive proof of a relationship between isoflavones and the prevention and treatment of prostatic disease can only come from prospective, randomized controlled clinical trials.

\section{Acknowledgements}

This study was supported by a grant from the National Institute of Health, USA (grant number 1R01 AR049439-01A1) and the Research Grant Council of Hong Kong.

\section{References}

1. Issacs JT \& Coffey D (1989) Etiology and disease process of benign prostatic hyperplasia. Prostate 2, Suppl., 33-50.

2. Ekman P (1989) BPH epidemiology and risk factors. Prostate 2, Suppl., 23-33.

3. Coward L, Barnes NC, Setchell KDR \& Barnes S (1993) Genistein, daidzein, and their B-glycoside conjugates. Antitumor isoflavones in soybean foods from American and Asian diets. J Agric Food Chem 41, 1961-1967.

4. Adlercreutz H, Bannwart C, Wahala K, Makela T, Brunow G, Hase T, Arosemena PJ, Kellis JT Jr \& Vickery LE (1993) Inhibition of human aromatase by mammalian lignans and isoflavonoid phytoestrogens. J Steroid Biochem Mol Biol 44, 147-153.

5. Leung SSF, Ho SC, Woo J, Lam TH \& Janus ED (1997) Hong Kong Adult Dietary Survey 1995. Hong Kong: Department of Paediatrics, Chinese University of Hong Kong. 
6. McCance RA (1978) McCance \& Widdowson's: The Composition of Foods, 4th ed. London: HMSO.

7. Yang Y, Wang G \& Pan X (2002) Institute of Nutrition \& Food Safety, China CDC. China Food Composition 2002. Peking: University Medical Press.

8. Dwyer JT, Goldin RB, Saul N, Gaultieri L, Barakat S \& Adlercreutz H (1994) Tofu and soy drinks contain phytoestrogens. J Am Diet Assoc 94, 739-743.

9. Anderson JW (1997) Estimated values for isoflavone content of selected soyfoods. Paper presented at the American Dietetic Association 80th Annual Meeting and Exhibition, 27-30 October, Boston, MA.

10. Barry MJ, Fowler FJ Jr, O'Leary MP, Bruskewitz RC, Holtgrewe HL, Mebist WK \& Cockett AT (1992) The American Urological Association symptom index for benign prostatic hyperplasia. J Urol 148, 1549-1557.

11. Chan AYT, Yiu MK \& Yiu TF (1999) Diagnosis of BPH and when to refer. Hong Kong Pract 21, 116-124.

12. Washburn RA (1993) The physical activity scale for the elderly (PASE): development and evaluation. J Clin Epidemiol 46, 153-162.

13. Census and Statistics Department (2003) Thematic Household Survey Report No.12: Health Status of Hong Kong Residents; Doctor Consultation; Hospitalization; Dental Consultation; Provision of Medical Benefits by Employers/Companies and Coverage of Medical Insurance Purchased by Individuals; Health Status of Institutional Residents and their Utilization of
Medical Services. Hong Kong SAR: Census and Statistics Department.

14. Jacobsen BK, Knutsen SF \& Fraser GE (1998) Does high soy milk intake reduce prostate cancer incidence? The Adventist Health Study (United States). Cancer Causes Control 9, $553-557$.

15. Hong SJ, Kim SI, Kwon SM, Lee JR \& Chung BC (2002) Comparative study of concentration of isoflavones and lignans in plasma and prostatic tissues of normal control and benign prostatic hyperplasia. Yonsei Med J 43, 236-241.

16. Brossner C, Petritsch K, Fink K, Auprich M, Madersbacher S, Adlercreutx H, Rehak P \& Petritsch P (2004) Phytoestrogen tissue levels in benign prostatic hyperplasia and prostate cancer and their association with prostatic diseases. Urology 64, 707-711.

17. Weber KS, Setchell KDR, Stocco DM \& Lephart ED (2001) Dietary soy-phytoestrogens decrease testosterone levels and prostate weight without altering $\mathrm{LH}$, prostate $5 \alpha$ reductase or testicular steroidogenic acute regulatory peptide levels in adult male Sprague-Dawley rats. J Endocrinol 170, 591-599.

18. Jarred RA, McPherson SJ, Jones MEE, Simpson ER \& Risbridger GP (2003) Anti-androgenic action by red cloverderived dietary isoflavones reduces non-malignant prostate enlargement in aromatase knockout (ArKO) mice. Prostate 56, 54-64.

19. Kurzer MS \& Xu X (1997) Dietary phytoestrogens. Annu Rev Nutr 17, 353-381. 